\title{
Formation and Regrowth of Intra-Abdominal Adhesions after Adhesiolysis: The Paradox of Surgical Adhesion-Reduction Strategies
}

\author{
D. Menzies M.C. Parker \\ Colchester General Hospital, Colchester, UK
}

We have followed with interest the publications of Swank et al. [1] concerning surgical adhesion-reduction strategies for the management of pelvic pain and wish to respond to their latest article, published in January 2004, which discusses the incidence/ extent of intra-abdominal adhesion formation/reformation following laparoscopic adhesiolysis.

The role of intra-abdominal adhesions in the development of chronic pelvic pain remains a matter of debate [2]. Similarly, the efficacy of surgical adhesion-reduction strategies for pain management has been disputed for some time [2]. This article adds to the growing body of evidence in favour of a link between adhesions and pelvic pain [3] and provides an important discussion of the merits of adhesiolytic strategies.

In two previous publications, the authors highlight the high risks of bowel perforation associated with adhesiolysis [4, 5] and the lack of difference in pain scores between patients managed by diagnostic laparoscopy or adhesiolytic laparoscopy [5]. In the later publication [5], the authors conclude that diagnostic laparoscopy is invaluable for identifying causes of pelvic pain, but warn that laparoscopic adhesiolysis is associated with considerable morbidity and is no more beneficial than diagnostic laparoscopy for pain relief.

In the present article, the authors argue that laparoscopic adhesiolysis significantly reduces the incidence, extent and severity of adhesions between peritoneal organs and the abdominal wall, and suggest that laparoscopy is less adhesiogenic than laparotomy, as has been asserted elsewhere [6]. However, they show no significant reduction in the quantity/quality of adhesions between organs and state that de novo adhesion formation occurred in $20 \%$ of patients. Although the patient cohort was small $(n=24)$, these data, in conjunction with their previous findings, highlight the limitations of surgical adhesion management strategies and emphasise the paradox that adhesiolysis may initiate adhesion development.

Numerous studies have drawn attention to the adhesive burden associated with open abdominal surgery [3, 7]. In our own investigations in the Surgical and Clinical Adhesions Research (SCAR) [8] and the more recent SCAR-2 $[9,10]$ studies, we have revealed the considerable burden and risk of adhesions following both laparoscopic and open abdominopelvic surgery.

We believe that, in the context of these studies, the findings presented here highlight the importance of preventive rather than curative strategies for adhesion control. By employing good surgical techniques and adhesion-reduction agents in concert with appropriate, minimally invasive access techniques, we may help to reduce this burden and minimise the risks of chronic pain, as well as small bowel obstruction, in patients who have undergone abdominopelvic surgery.

\section{References}

1 Swank DJ, Hop WC, Jeekel J: Reduction, regrowth, and de novo formation of abdominal adhesions after laparoscopic adhesiolysis: A prospective analysis. Dig Surg 2004;21:66-71.
2 Diamond MP, Freeman ML: Clinical implications of postsurgical adhesions. Hum Reprod Update 2001;7:567-576.

-3 diZerega GS: Biochemical events in peritoneal tissue repair. Eur J Surg Suppl 1997;577:1016.

-4 Swank DJ, van Erp WF, Repelaer van Driel OJ, Hop WC, Bonjer HJ, Jeekel J: Complications and feasibility of laparoscopic adhesiolysis in patients with chronic abdominal pain. A retrospective study. Surg Endosc 2002;16: 1468-1473.

-5 Swank DJ, Swank-Bordewijk SC, Hop WC, van Erp WF, Janssen IM, Bonjer HJ, Jeekel J: Laparoscopic adhesiolysis in patients with chronic abdominal pain: A blinded randomised controlled multi-centre trial. Lancet 2003; 361:1247-1251.

6 Operative Laparoscopy Study Group: Postoperative adhesion development after operative laparoscopy: evaluation at early second-look procedures. Fertil Steril 1991;55:700-704.

7 Menzies D, Parker M, Hoare R, Knight A: Small bowel obstruction due to postoperative adhesions: treatment patterns and associated costs in 110 hospital admissions. Ann R Coll Surg Engl 2001;83:40-46.

8 Parker MC, Ellis H, Moran BJ, Thompson JN, Wilson MS, Menzies D, McGuire A, Lower AM, Hawthorn RJ, O'Briena F, Buchan S, Crowe AM: Postoperative adhesions: Ten-year follow-up of 12,584 patients undergoing lower abdominal surgery. Dis Colon Rectum 2001; 44:822-829.

-9 Sunderland G: SCAR2 - The risk of adhesions following colorectal surgery (abstract). Colorectal Dis 2003;5:598.

10 Parker MC, Wilson MS, Menzies D, Clark D, Knight AD, Crowe AM: Adhesion related outcomes in 9,599 patients undergoing colon surgery between 1996 and 1998 (abstract). Colorectal Dis 2002

\section{KARGER}

Fax + 41613061234 E-Mail karger@karger.ch www. karger.com
(C) 2004 S. Karger AG, Basel 0253-4886/04/0216-0458\$21.00/0

Accessible online at: www. karger.com/dsu
Mr. Don Menzies

Colchester General Hospital

Turner Road

Colchester, Essex CO4 5JL (UK)

Tel. +44 1206 742629, Fax +44 1206 742030, E-Mail donmenzies@tinyworld.co.uk 
Reply

We would like to thank Menzies and Parker for their response on our article concerning the regrowth of adhesions after laparoscopic adhesiolysis [1]. Instead of surgical therapy, they argue for a preventive non-surgical strategy to solve the adhesion burden. We agree that the efficacy of surgical strategies for adhesion-related disorders, like infertility, bowel obstruction and chronic abdominal pain, remain at least a matter of debate.

Second-look laparoscopy after laparoscopic adhesiolysis for infertility uncovers the regrowth of adhesions in $55-100 \%$ of patients [2]. Although the chance of infertility is correlated with the severity of adnexal adhesions, the chance of pregnancy did not increase after early second-look laparoscopic adhesiolysis compared with that in patients who did not undergo re-laparoscopy and adhesiolysis [3].

Treatment of small bowel obstruction is predominantly the management of postoperative adhesions [4]. In more than $70 \%$ of patients small bowel obstruction was caused by adhesions, which in $35-87 \%$ of cases can be successfully lysed laparoscopically [5]. The conversion rate was $32 \%$ due to failure to identify the obstructing adhesion to an iatrogenic perforation, and due to technical difficulties. Moreover, in more than $50 \%$ of patients the obstruction recurred [6]. So, in bowel obstruction, surgical adhesiolysis treats a symptom, and that for a limited period of time, and is not the solution for the adhesion illness.

Like many other authors, we were convinced of the benefit of laparoscopic adhesiolysis for chronic abdominal pain. In our prospective study looking for predictive factors, 224 patients with chronic pain underwent laparoscopic adhesiolysis. Three months later, $74 \%$ of these patients were pain free $(40 \%)$ or had less pain (34\%) [7], a striking result for patients suffering from chronic pain for many years. Another study notes the incompleteness in $22 \%$ of 174 consecutive laparoscopic adhesiolysis procedures, besides the occurrence of $16(9 \%)$ ma- jor complications (perforations) [8]. Eighty percent of patients were pain free or had less pain, but the results were independent of the completeness of the adhesiolysis and related to the occurrence of complications. With new techniques (ultrasonic dissection; optiview trocar) the complication rate decreased to $5 \%$. We wanted to publish these results in order to stimulate colleagues in surgery to do laparoscopic adhesiolysis on patients with chronic pain. However, after a randomized study (forced by our statistician W.C.J. Hop and Prof. Jeekel to get a $\mathrm{PhD}$ ) we had to conclude that the results of laparoscopic adhesiolysis versus diagnostic laparoscopy only differ in complications and not in benefit [9]. This changes our opinion that laparoscopic adhesiolysis is no longer indicated for chronic abdominal pain.

A significant reduction in adhesions between organs and the abdominal wall was demonstrated in 24 patients at second-look re-laparoscopy a mean of 16 months after laparoscopic adhesiolysis for treatment of chronic pain [1]. This might partially explain the relief of pain after adhesiolysis of the adhesions fixed to the abdominal wall. No permanent reduction in adhesions between organs occurred, and that is probably the reason for the frequent recurrence of bowel obstructions.

Surgery is not the solution for the adhesion-related disorders and can even aggravate them, but the laparoscopic technique may assist in reducing the burden.

Menzies and Parker advocate the application of adhesion reduction agents, but their opinion can only be based on quantitative adhesion studies and that is not the same as clinical effectiveness. A randomized controlled trial to prove the benefit of these agents needs at least 5,700 patients and is cost-effective in case of a $16 \%$ reduction in adhesion-related admissions after 3 years and will cost GBP 300,000 [10]. A European trial can solve this question, perhaps with financial support from the National Health Services or from the EU? We would like to participate in such a trial.

\section{References}

1 Swank DJ, Hop WCJ, Jeekel J: Reduction, regrowth and de novo formation of abdominal adhesions after laparoscopic adhesiolysis: A prospective analysis. Dig Surg 2004;21:66-71.

$\checkmark 2$ Vrijland WW, Jeekel J, Van Geldorp HJ, Swank DJ, Bonjer HJ: Abdominal adhesions: intestinal obstruction, pain and infertility. Surg Endosc 2003; 17:1017-1022.

> Alborzi S, Motazedian S, Parsanezhad ME: Chance of adhesion formation after laparoscopic salpingo-ovariolysis: Is there a place for second-look laparoscopy? J Am Assoc Gynecol Laparosc 2003;10:172-176.

4 Wilson MS, Ellis H, Menzies D, Moran BJ, Parker MC, Thompson J: A review of the management of small bowel obstruction. Members of the Surgical and Clinical Adhesions Research Study (SCAR). Ann R Coll Surg Engl 1999;81:320-328.

$\checkmark 5$ Fischer CP, Doherty D: Laparoscopic approach to small bowel obstruction. Semin Laparos Surg 2002;9:40-45.

6 Barkan H, Webster S, Ozeran S: Factors predicting the occurrence of small-bowel obstruction. Am J Surg. 1995;70:361-365.

7 Swank DJ, Van Erp WFM, Repelaer van Driel OJ, Hop WCJ, Bonjer HJ, Jeekel J: A prospective analysis of predictive factors on the results of laparoscopic adhesiolysis in patients with chronic abdominal pain. Surg Laparosc Endosc Percutan Tech 2003;13:88-94.

$>8$ Swank DJ, Van Erp WFM, Repelaer van Driel OJ, Hop WCJ, Bonjer HJ, Jeekel J: Complications and feasibility of laparoscopic adhesiolysis in patients with chronic abdominal pain. A retrospective study. Surg Endosc 2002;10: 1468-1473

-9 Swank DJ, Swank-Bordewijk SCG, Hop WCJ, Van Erp WFM, Janssen IMC, Bonjer HJ, Jeekel J: Laparoscopic adhesiolysis in patients with chronic abdominal pain: A blinded randomised controlled multi-centre trial. Lancet 2003;361:1247-1251.

10 Wilson MS, Menzies D, Knight AD, Crowe AM: Demonstrating the clinical and cost effectiveness of adhesion-related strategies. Colorectal Dis 2002;4:355-360. 